\title{
Slik kan beboere på sykehjem bli mer aktive
}

Beboere på sykehjem har godt av å være i aktivitet, og noen trenger også å trene seg opp etter for eksempel et slag. Gode rutiner for å aktivisere beboere, samt opplæring av ansatte, er viktig for at beboerne skal få være i aktivitet hver dag.

\section{Forfattere}

Elisabeth Telenius

Fysioterapeut

Fagområde demens, Nasjonal kompetansetjeneste for aldring og helse

Randi Granbo

Fysioterapeut og førstelektor

Institutt for nevromedisin og bevegelsesvitenskap, Norges teknisk-naturvitenskapelige

universitet

Jorunn Helbostad

Fysioterapeut, professor og instituttleder

Institutt for nevromedisin og bevegelsesvitenskap, Norges teknisk-naturvitenskapelige universitet

Birgitta Langhammer

Fysioterapeut og professor

Institutt for fysioterapi, Oslomet - storbyuniversitetet

\begin{tabular}{l|l} 
Sykehjem & Fysisk aktivitet
\end{tabular}

Sykepleien 2019 107(75017)(e-75017)

DOI: https://doi.org/10.4220/Sykepleiens.2019.75017

Hovedbudskap 
«Leve hele livet»-reformen slår fast at helsetjenestene skal bidra til at eldre kan bevare eller øke sin mulighet til å fungere i hverdagen. Vi ønsker med denne artikkelen å vise betydningen av tilrettelagt fysisk aktivitet og trening for beboere på sykehjem og gi noen praktiske råd for tilrettelegging og gjennomføring av aktiviteter.

Stortingsmelding nr. 25 «Mestring, muligheter og mening» (1) vektlegger aktiv omsorg med kultur, aktivitet og trivsel som helt sentrale og grunnleggende elementer i et helhetlig omsorgstilbud. Viktigheten av aktivitet blir også løftet frem i den nye kvalitetsreformen for eldre, «Leve hele livet», som regjeringen arbeider med i disse dager (2). Den nye kvalitetsreformen har som overordnet mål at personer over 65 år som bor hjemme eller i institusjon, skal få bedre hjelp og støtte til å mestre livet og til å ha en god og innholdsrik hverdag.

\section{Bra å være aktiv}

Sammenhengen mellom fysisk aktivitet og helse er godt dokumentert for befolkningen generelt og for eldre personer. Dessuten har det vist seg at stillesitting i seg selv er en risikofaktor for dårlig helse. Økt satsing på hjemmebaserte tjenester har resultert i at de som nå får en sykehjemsplass, er eldre enn tidligere, de har flere sykdommer og ofte et mer komplekst sykdomsbilde.

Konsekvenser av denne utviklingen er at beboere i sykehjem i mindre grad klarer å ivareta sine grunnleggende behov for bevegelse og fysisk aktivitet. Flytting fra eget hjem til sykehjem medfører dessuten store endringer i hverdagsrutinene, og mange oppgaver som personen tidligere måtte greie selv, blir plutselig tatt over av andre. Resultatet blir et ytterligere funksjonstap som skjer raskere enn nødvendig på grunn av en passiv og inaktiv livsstil (3).

\section{«Å kunne bevege seg er et grunnleggende behov - også for sykehjemsbeboere.»}


Å kunne bevege seg er et grunnleggende behov - også for sykehjemsbeboere. Dette behovet ivaretas best gjennom deltakelse i daglige gjøremål og gjennom tilrettelagte aktiviteter (4).

«Forskrift om en verdig eldreomsorg» slår fast at tjenestene skal bidra til at eldre kan bevare eller øke sin mulighet til å fungere i hverdagen (5). Det er derfor viktig å ha fokus på bevegelse og fysisk funksjon hos beboere i sykehjem.

Vi ønsker med denne artikkelen å løfte frem kunnskapsgrunnlaget som viser betydningen av tilrettelagt fysisk aktivitet og trening for denne gruppen og gi noen praktiske råd for tilrettelegging og gjennomføring av fysisk aktivitet.

\section{Trening eller fysisk aktivitet?}

Fysisk aktivitet defineres i internasjonal faglitteratur som: All kroppslig bevegelse produsert av skjelettmuskulatur som resulterer i en vesentlig økning av energiforbruket utover hvilenivå.

Trening defineres som: Fysisk aktivitet $\mathrm{i}$ fritiden som gjentas regelmessig over tid med målsetting å forbedre for eksempel form, prestasjon eller helse. 
I forbindelse med trygghetsstandardprosjektet har Helsedirektoratet gitt HiOA (nå Oslomet storbyuniversitetet) og NTNU i oppdrag å lage en kunnskapsbase som skal beskrive effekt av fysisk aktivitet og trening, aktivitetsnivå og indikatorer opp mot funksjonsnivå. Gjennom et omfattende søk etter relevante forskningsartikler har vi laget en oppdatert kunnskapsbase som gir en oversikt over dokumentert effekt og belyser betydningen av fysisk aktivitet og trening for sykehjemsbeboere. Rapporten kan leses i sin helhet

på https://skriftserien.hioa.no/index.php/skriftserien/art icle/view/86/85 (6).

\section{Inaktivitet får konsekvenser}

«Det å gjøre noe krever energi, og hvis du ikke beveger deg, så får du stadig mindre energi. Det er en ond sirkel.» (Beboer i sykehjem)

Aktivitetsnivået til beboere i sykehjem har ikke blitt undersøkt systematisk i Norge, men ifølge Helsedirektoratet har hjemmeboende eldre over 70 år lavere fysisk aktivitetsnivå sammenliknet med yngre hjemmeboende (8). Det er nærliggende å tro at personer i sykehjem, som er sykere, mer skrøpelige og mindre selvstendige, er enda mer inaktive. Denne inaktiviteten får store fysiske, psykiske og sosiale konsekvenser. Tap av fysisk funksjon fører til nedsatt livskvalitet, økt risiko for fall, brudd, depresjon, større omsorgsbehov og høyere utgifter til helsetjenester (9).

\section{三 «Mellom 10 og 20 prosent av fallene i sykehjem fører til alvorlige skader.»}


Eldre som bor i sykehjem, faller tre ganger så ofte som hjemmeboende eldre (10). Mellom 10 og 20 prosent av fallene i sykehjem fører til alvorlige skader. Tidligere fall både med og uten skader kan føre til frykt for nye fall og dermed en vegring mot å bevege seg, med det resultat at fallfaren øker ytterligere. Smerter og plager i muskler og skjelett bidrar også til lavere aktivitetsnivå og kan lede til en ond sirkel der man ikke beveger seg fordi det gjør vondt, og man får mer vondt fordi man ikke beveger seg. I en rapport fra Buskerud oppga 4555 prosent av sykehjemsbeboere fysisk smerte, lokalisert til ledd, muskler og bindevev (11).

Fysisk aktivitet og trening spiller en viktig rolle for å opprettholde eller bedre fysisk funksjon. I tillegg kan fysisk aktivitet bedre fysisk og mental helse, sosialt liv og livskvalitet. En norsk studie har funnet en sammenheng mellom god fysisk funksjon og høyere livskvalitet hos beboere i sykehjem (12). Studier basert på intervjuer av beboere i sykehjem har gjentatte ganger vist at uansett diagnose og funksjonsproblem, synes beboerne det er viktig å beholde evnen til å være mobil, og at det å kunne forflytte seg selv gir en følelse av selvstendighet, frihet og autonomi (7).

\section{Spesielt sårbare beboere}

Man antar at omtrent 80 prosent av personer som bor i sykehjem, har demens, og mange lever med senskader etter hjerneslag $(13,14)$. Beboere med disse sykdomstilstandene er spesielt sårbare for funksjonstap. Tilrettelegging for fysisk aktivitet og tilbud om opptrening er derfor ekstra viktig.

Sykehjemsbeboere med demens er en av de gruppene med størst hjelpebehov. Demenssykdom gir ofte symptomer på tre ulike områder: kognisjon, atferd og mobilitet. Inaktivitet hos denne gruppen fører til raskere nedgang i fysisk funksjon og mer uttalte atferdssymptomer (som apati, uro og depresjon) enn hos kognitivt friske personer (15). 
Fysisk aktivitet og trening er effektive virkemidler for å opprettholde og forbedre ADL-funksjon, balanse og mobilitet hos personer med demens og kan også ha positiv effekt på atferdssymptomer $(16,17)$. Studier i sykehjem har vist at personer med demens kan motta tilrettelagt instruksjon, og de kan være motiverte for å delta på regelmessig trening over en lengre periode (18).

\section{Aktiviteter i dagliglivet}

Aktiviteter i dagliglivet, forkortet ADL, er meningsfulle og målrettede handlinger som mennesker utfører på ulike livsområder.

Kilde: Store medisinske leksikon

Med en økende aldrende befolkning vil antallet personer med hjerte-/karlidelser, inklusive hjerneslag, øke. Rehabilitering etter hjerneslag har alltid som mål å optimalisere gjenværende funksjon, og de med størst prosentvis reduksjon i funksjon har bedre rehabiliteringspotensial enn de med mindre funksjonstap (19).

Pasienter med store utfall etter slaget blir ofte ikke prioritert for deltakelse i videre trening etter at den initiale rehabiliteringen er ferdig. I stedet blir de ofte utsatt for «godhet» i form av mer hjelp enn de har behov for, noe som gjør personen til en passiv mottaker av pleie i stedet for en aktiv deltaker. Den følgende inaktiviteten øker risikoen for at bedringsprosessen stopper opp. Funksjoner man har trent opp umiddelbart etter slaget, tapes da fort. 
Det enkle prinsippet «use it or lose it» gjelder for alle, men spesielt for de med dårligst funksjon der en treningsinnsats gir prosentvis større uttelling enn hos mer funksjonsdyktige $(19,20)$. Daglig fysisk og kognitiv aktivitet er nødvendig for å vedlikeholde gjenvunnet fysisk funksjon. Det er derfor viktig at også personer med hjerneslag i sykehjem blir tilbudt deltakelse i dagligdagse oppgaver og i generell fysisk aktivitet og utholdenhets- og styrketrening.

\section{Fall kan forebygges}

Det er mange grunner til at eldre faller, og årsakene er ofte sammensatte. Det skilles gjerne mellom indre og ytre risikofaktorer for fall.

De indre faktorene ser ut til å spille den viktigste rollen. Disse har med pasientens fysiske og mentale helse og atferd å gjøre, for eksempel balansefunksjon, beinstyrke og syn.

Av ytre risikofaktorer i fellesarealer kan nevnes manglende støttehåndtak og tilgang til hvilemuligheter samt uhensiktsmessig plassering av møbler og utstyr, glatte gulv og dårlig belysning. Sammensatte tiltak som inneholder blant annet opplæring av ansatte og beboere, gjennomgang av medikamentbruk og fysisk trening med vekt på styrke og balanse, kan forebygge fall i sykehjem (21).

\section{$\equiv$ «Dødeligheten etter et brudd er nær 80 prosent.»}

Den alvorligste fallskaden hos eldre som overlever et fall, er lårhalsbrudd. Det er cirka 9000 lårhalsbrudd i Norge per år (22). Lårhalsbrudd hos personer som allerede bor i sykehjem, er alvorlig, og dødeligheten etter et brudd er nær 80 prosent (23). Det er derfor viktig å forebygge at personer i sykehjem faller. 
Prognosen for å gjenopprette tidligere funksjon er også dårligere for sykehjemsbeboere enn for dem som bor hjemme. Beboere i sykehjem som pådrar seg hoftebrudd, blir ofte sendt tilbake til sykehjemmet få dager etter hofteoperasjonen, og ansvaret for tidlig mobilisering og rehabilitering faller dermed på sykehjemmets ansatte.

Beboere i sykehjem trenger lang rehabiliteringstid etter et hoftebrudd. Det er viktig å motivere den eldre personen til mobilisering så raskt som mulig etter et hoftebrudd. Risikoen for komplikasjoner og sjansene for å få tilbake funksjon reduseres for hver dag i senga. For personer som trengte assistanse til mobilisering allerede før bruddet, øker risikoen for død med nesten 20 prosent dersom tiden i sengen forlenges (24).

\author{
Redusert muskelstyrke \\ Redusert utholdenhet \\ Nedsatt sirkulasjon \\ Tap av beinmasse \\ Leddene blir stive \\ Trykksår \\ Redusert hostekraft \\ Tregere fordøyelse \\ Urininkontinens
}

Konsekvenser av inaktivitet

\title{
Legg til rette for aktiviteter
}

Beboere i sykehjem med redusert fysisk kapasitet er avhengig av hjelp fra omgivelsene for å ivareta sine grunnleggende bevegelsesbehov. Bevegelse er viktig både for å ivareta fysiologiske prosesser i kroppen og for velvære. Det er derfor nødvendig å iverksette strategier som legger til rette for økt bevegelse og aktivitet hos denne målgruppen. Dette vil kreve tilrettelegging og muligens endring av sykehjemmets og den enkelte avdelingens daglige rutiner. 
En bevissthet rundt, og kunnskap om, betydningen av daglig fysisk aktivitet hos de ansatte er helt sentralt. Fysisk aktivitet og trening hos eldre dekkes i variert utstrekning på de forskjellige helseprofesjonsutdanningene, så det er av avgjørende betydning at sykehjemmene selv setter dette på dagsordenen.

\section{三 «Det er nødvendig med en plan for hvordan den enkelte beboer kan delta i daglige gjøremål.»}

Det er nødvendig med en plan for hvordan den enkelte beboer kan delta i daglige gjøremål ut fra sine ressurser og forutsetninger. Ansvaret for dette ligger fremfor alt hos ledelsen på sykehjemmet, men også hos hver enkelt ansatt. Rutiner for hvordan fysisk aktivitet skal ivaretas, bør utarbeides av ledelsen i samarbeid med de ansatte (25).

Det er naturlig å introdusere og informere om sykehjemmets vektlegging av fysisk aktivitet også ved rekruttering av nye omsorgsarbeidere, for å sikre at nyansatte vil legge til rette for daglig fysisk aktivitet for beboerne.

\section{Smarte verktøy}

Sykehjemsbeboere er en heterogen gruppe. Av den grunn er det ikke mulig å foreskrive ett aktivitets- og treningsprogram som vil møte alles behov. Tilrettelegging av fysiske aktiviteter må individualiseres og skreddersys. For å motivere til aktivitet må den ansatte kjenne beboeren godt. 
Vurdering av fysisk funksjon ved innflytting til sykehjemmet og kartlegging av interesser og tidligere aktivitetsnivå vil gjøre det enklere å legge til rette for individuell og tilpasset aktivitet. Ny vurdering vil være nødvendig ved endring i funksjonsnivået, eksempelvis etter akutt sykdom eller en fallhendelse. En slik rutine vil gi ansatte mulighet for bedre innsikt i hva den nye beboeren faktisk greier å utføre selv, og dermed bidra til at beboerne ikke fratas mulighetene for egenaktivitet.

En funksjonsvurdering må bestå av en observasjon av hva personen er i stand til å gjøre på egen hånd og eventuelt hvilken grad av bistand som trengs for å utføre aktiviteten. For å få et realistisk bilde av den enkelte beboers funksjonsnivå ved innkomst i sykehjem og/eller ved endring av funksjonsnivå, er det nødvendig å observere hvordan personen er i stand til å gjennomføre noen praktiske oppgaver og aktiviteter og ikke bare innhente slik informasjonen gjennom å stille spørsmål.

Forslag til aktiviteter som bør kartlegges ved observasjon av selve utførelsen:

\section{Funksjonsvurdering}

Personlig hygiene:

Kan stå ved vasken

\section{På- og avkledning:}

Kan ta på og av seg klær i sittende eller stående stilling?

\section{Toalettbesøk:}

Kan gå til og fra toalettet med eller uten ganghjelpemiddel 


\section{Forflytning:}

Kan forflytte seg ut og inn av seng

Greier å reise seg opp fra stol

Bevege seg innendørs

Kan gå i avdelingen med eller uten

hjelpemiddel

\section{Bevege seg utendørs:}

Kan forsere dørterskler

Kan gå i trapp med eller uten hjelpemiddel

Kan gå utendørs (forsere kantsteiner, ujevnt underlag)

Rangeres 1: selvstendig 2: med tilsyn 3: med hjelp 4: kan ikke utføre

Med utgangspunkt i kartleggingen og samtalen om hva slags aktiviteter beboeren foretrekker, bør det utarbeides en ukeplan over hva slags aktiviteter personen skal delta i eller på. Planen for aktiviteter kan med fordel henges opp på rommet til den enkelte beboer for å være synlig for personen selv, pårørende og andre besøkende, og ikke minst omsorgspersonalet.

Det kan også være en god idé å innføre bruk av en aktivitetsdagbok hvor aktivitetene som beboeren har vært med på, skrives ned. Både planen og boka kan være kilde til samtaletema og motivasjon, og vil dessuten kunne veilede personalet, for eksempel i valg av hjelpemiddel som rullator eller rullestol når beboer skal følges til spisesalen.

\section{Råd om aktivitet og trening}


Som påpekt i den nye kvalitetsreformen for eldre, «Leve hele livet» (2), er deltakelse i alle typer aktiviteter viktig for å oppleve mestring, fellesskap, meningsfull hverdag, livskvalitet og opprettholde fysisk funksjon. Ifølge stortingsmeldingen bør eldre få tilbud om minst én time aktivitet daglig med bakgrunn i egne interesser, ønsker og behov. Aktiviteten skal gi gode opplevelser og øyeblikk i hverdagen og stimulere sanser og minner, bevegelse og deltakelse i sosialt fellesskap. Fysisk aktivitet er med og opprettholder fysisk funksjon og er derfor vesentlig også for deltakelse i andre aktiviteter.

I tråd med anbefalinger gitt i USA og en rekke europeiske land (26) gir vi råd på to nivåer om hvordan opprettholde fysisk funksjon hos beboere i sykehjem. Nivå 1 har som formål å begrense inaktiv livsstil for alle sykehjemsbeboere. Nivå 2 inneholder råd om fysisk trening for spesielt sårbare grupper av sykehjemsbeboere.

\section{Nivå 1: Opprettholde daglige aktiviteter for å begrense inaktivitet}

Motivasjon og glede er viktige nøkkelord når en skal bidra til mer aktivitet blant beboerne. Dessuten vil det for mange være viktig å ha en hensikt med aktiviteten, for eksempel å ta en tur for å se på blomstene eller kunstutsmykning på en annen avdeling, drikke kaffen i en annen salong enn den nærmeste, gå ned i resepsjonen for å se på folk som kommer og går, og sørge for så aktiv deltakelse som mulig i stell og av- og påkledning. 
Aktivitetene som er foreslått til bruk i

funksjonsvurdering (tekstboks ovenfor), er eksempler på tiltak som bør inkluderes i hverdagsrutinen.

Personalet må la personene få delta i enkle, daglige gjøremål som å dekke bord, brette håndklær og liknende. Det er også fint å oppmuntre pårørende som er på besøk, til å være fysisk aktive sammen med beboeren. Gå en tur - gjerne ut i frisk luft og lys. Organiserte gruppeaktiviteter, for eksempel tur i sansehage eller innendørs bowling, er også viktige bidrag for å øke det fysiske aktivitetsnivået og redusere stillesittingen.

\section{Nivå 2: Fysisk trening}

Personer med forhøyet fallrisiko og personer med en demenssykdom bør få tilbud om tilpasset trening for å bedre styrken og balansen sin som et ledd i det fallforebyggende arbeidet. Dessuten bør personer som gjennomgår akutte hendelser som påvirker fysisk funksjonsnivå, for eksempel hoftebrudd eller hjerneslag, bli tilbudt tilrettelagt og målrettet trening for å gjenvinne så mye funksjon som mulig. Vi anbefaler både sammensatt trening (styrke-, kondisjons- og balansetrening) og styrketrening alene. Intensiteten bør være av moderat grad og vare i 30 til 60 minutter og gjennomføres to ganger i uken.

\section{Vi gir følgende råd}

- Individuell vurdering av fysisk funksjon ved innkomst og ved endringer $\mathrm{i}$ funksjonsnivå.

- Innføring av rutinemessige tiltak som begrenser inaktivitet i dagliglivet for alle beboere.

- Tilbud om rutinemessig opptrening ved en del kroniske tilstander/akutte hendelser.

- Økt kompetanse hos omsorgspersonalet og bevisstgjøring av betydningen av 


\section{Referanser}

1. St.meld. nr. 25 (2005-2006) Mestring, muligheter og mening. Oslo: Helse- og omsorgsdepartementet; 2006. Tilgjengelig fra: https://www.regjeringen.no/no/dokumenter/stmeld-nr25-2005-2006-/id200879/ (nedlastet 18.01.2019).

2. Meld. St. nr.15 (2017-2018) Leve hele livetreformen. Oslo: Helse- og omsorgsdepartementet; 2018. Tilgjengelig fra: https://www.regjeringen.no/no/tema/helse-ogomsorg/innsikt/leve-hele-livet/id2547684/\# (nedlastet 18.01.2019).

3. Hawkins RJ, Prashar A, Lusambili A, Ellard DR, Godfrey M. 'If they don't use it, they lose it': how organisational structures and practices shape residents' physical movement in care home settings. Ageing \& Society. 2017:1-26.

4. Granbo R, Helbostad JL. Hvordan ivareta sykehjemsbeboernes behov for bevegelse? Tidsskr Nor Lægeforen. 2006;15;126:1934-6.

5. Regjeringen. Forskrift om en verdig eldreomsorg (Verdighetsgarantien) [internett]. Oslo: Helse- og omsorgsdepartementet 15.11.2010. Tilgjengelig fra: https://www.regjeringen.no/no/dokumenter/Forskriftom-en-verdig-eldreomsorgverdighetsgarantien/id624655/

6. Telenius EW, Langhammer B, Helbostad JL, Granbo R. Fysisk aktivitet og trening på sykehjem. Rapport utarbeidet ifm. pilotprosjekt trygghetsstandard på sykehjem, regi Helsedirektoratet. 2017. Tilgjengelig fra:

https://skriftserien.hioa.no/index.php/skriftserien/articl e/view/86/85 
7. Olsen CF, Telenius EW, Engedal K, Bergland A. Increased self-efficacy: the experience of highintensity exercise of nursing home residents with dementia-a qualitative study. BMC health services research. 2015;15(1):379.

8. Helsedirektoratet. Fysisk aktivitet og sedat tid blant voksne og eldre i Norge Nasjonal kartlegging 2014-15. Oslo: Helsedirektoratet; 2015. Tilgjengelig fra: https://helsedirektoratet.no/publikasjoner/fysiskaktivitet-og-sedat-tid-blant-voksne-og-eldre-i-norgenasjonal-kartlegging-201415 (nedlastet 18.01.2019).

9. Tomey KM, Sowers MR. Assessment of physical functioning: a conceptual model incompassing environmental factors and individual compensation strategies. Phys Ther. 2009;89(7):705-14.

10. Rubenstein LZ, Josephson KR, Robbins AS. Falls in the nursing home. Annals of internal medicine. 1994;121(6)442-51.

11. Gran SV. Eldre og smerter - en studie av eldres opplevelse av smerter: et samarbeidsprosjekt mellom kommunehelsetjenesten i Nedre Buskerud og Høgskolen i Buskerud, Avdeling for helsefag. Rapporter Høgskolen i Buskerud 2009 nr. 72. ISBN 978-82-91116-95-2

12. Telenius EW, Engedal K, Bergland A. Physical performance and quality of life of nursing-home residents with mild and moderate dementia. Int $\mathrm{J}$ Environ Res Public Health. 2013 desember 2;10(12):6672-86.

\section{Bergh S, Holmen J, Saltvedt I,} Tambs K, Selbæk G. Dementia and neuropsychiatric symptoms in nursing-home patients in Nord-Trøndelag County. Tidsskr Nor Legeforen- 2012;132(17):1956-9. 
14. Brown RD Jr, Ransom J, Hass S, Petty GW, O'Fallon WM, Whisnant JP, Leibson CL. Use of nursing home after stroke and dependence on stroke severity: a population-based analysis. Stroke. 1999;30(5):924-9. PubMed PMID: 10229721

15. Kang H. Correlates of social engagement in nursing home residents with dementia. Asian nursing research. 2012;6(2):75-81.

16. Forbes D, Forbes SC, Blake CM, Thiessen EJ, Forbes S. Exercise programs for people with dementia. Cochrane Database of Systematic Reviews. 2015 desember 4;(12):CD006489

17. De Souto Barreto P, Demougeot L, Pillard F, Lapeyre-Mestre M, Rolland Y. Exercise training for managing behavioral and psychological symptoms in people with dementia: a systematic review and metaanalysis. Ageing Res Rev. 2015 november;24(Pt B):274-85.

18. Telenius EW, Engedal K, Bergland. Effect of a high-intensity exercise program on physical function and mental health in nursing home residents with dementia: an assessor blinded randomized controlled trial. PLoS One. 2015 mai 14;10(5):e0126102.

19. Langhammer B, Lindmark B. Functional exercise and physical fitness post stroke: the importance of exercise maintenance for motor control and physical fitness after stroke. Stroke Research and Treatment. vol. 2012, Article ID 864835

20. Lee K, Cho E. Activities of daily living and rehabilitation needs for older adults with a stroke: a comparison of home care and nursing home care. Japan Journal Of Nursing Science. 2017;14(2):103-11. 
21. Vlaeyen E, Coussement J, Leysens G, Van der Elst E, Delbaere K, Cambier D, Dejaeger E.

Characteristics and effectiveness of fall prevention programs in nursing homes: a systematic review and meta-analysis of randomized controlled trials. Journal of the American Geriatrics Society. 2015;63(2):21121.

22. Sogaard AJ, Holvik K, Meyer HE, Tell GS, Gjesdal CG, Emaus N, Grimnes G, Schei B, Forsmo S, Omsland TK. Continued decline in hip fracture incidence in Norway: a NOREPOS study.

Osteoporosis International. 2016 juli;27(7):2217-22.

23. Neuman MD, Silber JH, Magaziner JS, Passarella MA, Mehta S, Werner RM. Survival and functional outcomes after hip fracture among nursing home residents. JAMA Intern Med.

2014;174(8):1273-80.

24. Siu AL, Penrod JD, Boockvar KS, Koval K, Strauss E, Morrison RS. Early ambulation after hip fracture: effects on function and mortality. Archives of Internal Medicine. 2006;166(7):766-71.

25. Shield RR, Looze J, Tyler D, Lepore M, Miller SC. Why and how do nursing homes implement culture change practices? Insights from qualitative interviews in a mixed methods study. J Appl Gerontol. 2014 september;33(6):737-63.

26. De Souto Barreto P, Morley JE, Chodzko-Zajko W, H Pitkala K, Weening-Djiksterhuis E, RodriguezMañas L, Barbagallo M, Rosendahl E, Sinclair A, Landi F, Izquierdo M, Vellas B, Rolland Y. Recommendations on physical activity and exercise for older adults living in long-term care facilities: a taskforce report. J Am Med Dir Assoc. 2016 mai 1;17(5):381-92. 
27. Bouchard C, Shephard RJ, Stephens T. Physical Activity, fitness and health. International proceedings and concensus statement. England: Human Kinetics Publishers; 1994. s.77-88. 